\title{
Guest editorial: the seven wonders of erythropoiesis
}

\author{
Kenichi Sawada
}

Received: 24 December 2010/Accepted: 27 December 2010/Published online: 12 January 2011

(c) The Japanese Society of Hematology 2011

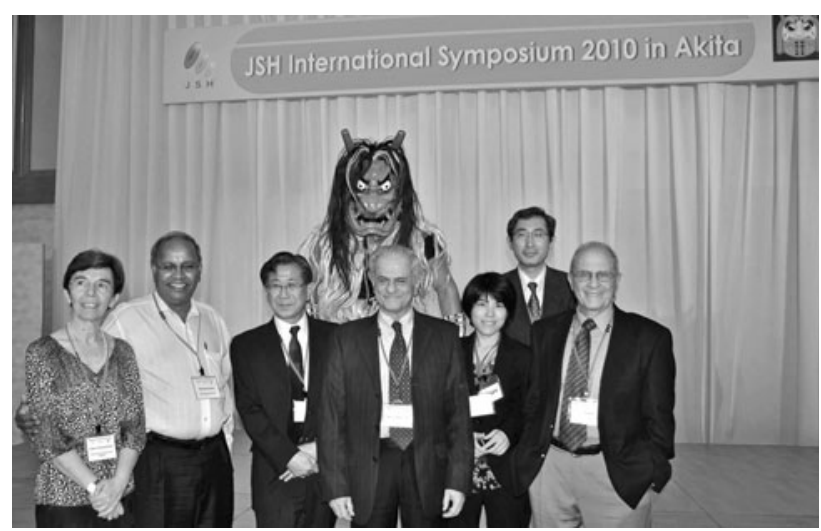

This month's issue introduces a special series of Progress in Hematology (PIH) reviews by seven outstanding scientists, providing comprehensive overviews of recent progress in seven aspects of erythropoiesis. A number of new findings in this rapidly evolving field are the focus this editorial feature, written by cutting-edge scientists invited to the 1st Annual International Symposium of The Japanese Society of Hematology (JSH) in Akita on 16-17 July 2010. The JSH International Symposium series focuses on outstanding scientific fields in each region of Japan, and encourages researchers to communicate and exchange knowledge and ideas, in the hope of contributing to advances in the selected field in both Japan and the rest of the world. This first year's Scientific Program included cutting-edge scientific presentations by an outstanding

K. Sawada $(\bowtie)$

Department of Hematology, Nephrology, and Rheumatology,

Akita University Graduate School of Medicine,

Akita, Akita 010-8543, Japan

e-mail: ksawada@doc.med.akita-u.ac.jp group of speakers in seven sessions over a 2-day period. Oral and poster presentations by future leaders in the study of erythropoiesis were also a highlight of the meeting. The seven sessions were organized along the theme of "the Seven Wonders of Erythropoiesis", acronymically titled Enucleation, Ribosomal proteins, Yield (of red cells), Transcription factors, Heme and iron, Red cell aplasia, and Oligodeoxynucleotide (ODN) and micro RNA, or "ERYTHRO". There has been much progress in recent years toward developing a better understanding of these aspects of erythropoiesis, as well as applications at the frontiers of medical science. This International Symposium also represented the start of the 1st JSH-EHA Joint Educational Program. These seven reviews will appear in PIH across two volumes of the International Journal of Hematology.

\section{Enucleation}

Enucleation of mammalian erythroblasts is thought to involve a process similar to cytokinesis. The molecular bases of enucleation and erythroblastic islands, as well as the erythropoietic niches have been explored intensively in recent years [1, 2]. However, the structural organization of a number of additional transmembrane proteins has yet to be fully defined. In this issue, Mohandas et al. [3] throw new light on the evolution of unique features of the red cell membrane, and introduce a new strategy for distinguishing unambiguously between erythroblasts at successive developmental stages. These findings provide unique insights into the genesis of red cell membrane function during erythroblast differentiation, and offer a means of defining stage-specific defects in erythroid maturation in inherited and acquired red cell disorders and bone marrow failure syndromes. 


\section{Ribosomal proteins}

The finding that congenital mutations in ribosomal protein S19 and other genes encoding ribosomal proteins cause Diamond-Blackfan anemia, a disorder characterized by hypoplastic, macrocytic anemia [4] remains as exciting today as it was at the time of its discovery. Ribosomopathies compose a collection of disorders in which genetic abnormalities cause impaired ribosome biogenesis and function, resulting in specific clinical phenotypes, i.e., Schwachman-Diamond syndrome, dyskeratosis congenita, cartilage hair hypoplasia, and Treacher Collins syndrome [5]. The 5q- syndrome, a subtype of myelodysplastic syndrome, caused by a somatically acquired deletion of chromosome 5q, leads to haploinsufficiency of the ribosomal protein RPS14 and an erythroid phenotype highly similar to that seen in Diamond-Blackfan anemia [6]. In this issue, Narla et al. deepen our understanding both of ribosome defects in disorders of erythropoiesis and of acquired abnormalities in ribosome function, which have been implicated more broadly in human malignancies. The p53 pathway provides a surveillance mechanism for protein translation and genome integrity, and is activated by defects in ribosome biogenesis. This pathway appears to be a critical mediator of many of the clinical features of ribosomopathies.

\section{Yield (of red cells)}

The production of transfusable red blood cells (RBCs) in vitro remains something of a Holy Grail, as in many countries the supply of RBCs remains insufficient. Several teams of investigators have already taken up this challenge $[7,8]$, seeking to generate immortalized erythroid cell lines able to produce transfusable RBCs in vitro, which, were they to be established, would be an immensely valuable resource. Establishment of embryonic stem cell-derived erythroid progenitor cell lines represents one promising approach to the production of functional red blood cells [9]. In this issue, Nakamura surveys the possibilities of establishing useful cell lines committed to specific lineages other than hematopoietic progenitors from human ES cells.

The in vivo regulation of erythropoiesis involves the integration of a range of intrinsic and extrinsic cues. The macrophage that sits at the heart of the erythroblastic island is known to be centrally important to normal differentiation and the support of erythroid development [1]. However, the contributions of other cell types found within the local bone marrow microenvironment, including osteoblasts, osteoclasts [10], adipocytes [11], and endothelial cells [12], and developing hematopoietic cells, remain largely unclear. The dynamic interaction and coordination between erythroid development and skeletal homeostasis, particularly in the setting of erythroid demand, remains a particularly stimulating discovery. In this issue, Walkley elucidates a centrally regulated axis with roles in physiology, pharmacology, and the pathology of anemia states.

\section{Transcription factors}

Considerable effort has been put into understanding the regulation of erythroid differentiation, and recent discoveries have clearly shown that lineage-specific transcription factor networks are essential for the proper differentiation of erythroid cells, and that erythropoiesis is largely mediated by a relatively small number of lineage-restricted transcription factors, including GATA-1, SCL/TAL1, LMO2, LDB1, and KLF1 [13]. The transcription factors GATA1 and GATA2 are involved in regulatory networks controlling erythroid gene expression, and importantly, expression of the Gatal and Gata2 genes is itself under the control of such regulatory networks [14]. In this issue, Suzuki et al. provide an overview of the mechanisms underlying Gata1 and Gata2 gene regulation during erythropoiesis, and the physiological significance of their dynamic transcriptional control.

\section{Heme and iron}

Mammalian iron homeostasis must be regulated closely to ensure that this essential element is available for use, but at the same time prevented from promoting the formation of toxic radicals [15]. Over the last decade, a number of central players in iron homeostasis have been introduced, helping to tie together previously discrete threads of knowledge. Typical examples of these include transferrin receptor 2 (TFR2) (2000) [16], a homolog of TFR1 that mediates cellular uptake of transferrin-bound iron in most cells; hepcidin (2001) [17, 18], a secreted peptide synthesized mainly by the liver that is a major regulator of iron metabolism; ferroportin (2004) [19], the only known vertebrate iron exporter; and hemojuvelin (2005) [20], a co-receptor of the bone morphogenetic protein (BMP) ligand, BMP-6, which is associated with a robust activation of hepcidin transcription. In this issue, Kaplan et al. explain the role of hepcidin and ferroportin in association with human disorders, involving either overloads or deficiencies of iron, while Camaschella and Pagani shine a light on the dual relationship between iron and erythropoiesis through the lens of spontaneous and engineered animal models of iron disorders. 


\section{Red cell aplasia and oligodeoxynucleotide (ODN) and micro RNA}

Pure red cell aplasia (PRCA) is a syndrome characterized by a severe normocytic anemia, reticulocytopenia, and an absence of erythroblasts in otherwise normal bone marrow. Primary PRCA, and secondary PRCA that has proven unresponsive to treatment of the underlying disease, is treated as an immunologically mediated disease. Although vigorous immunosuppressive treatments induce and maintain remissions in a majority of patients, these carry an increased risk of serious complications. In this symposium, based on a nationwide survey in Japan, current strategies for the treatment of PRCA were introduced in a presidential lecture. Although this issue is not reviewed in this PIH series, relevant articles can be found elsewhere [21, 22] as can focused articles on idiopathic [23], thymoma-associated [24], large granular lymphocyte leukemia-associated [25] and lymphoma-associated PRCA [26].

Oligodeoxynucleotides (ODN) are another deserving wonder that does not appear in this PIH series. One of the highlights of the meeting was the oral and poster presentations by promising young researchers in the field of erythropoiesis. In this symposium, Guo et al. made the case for the selective inhibition of erythroid growth and downregulation of the expression of erythropoietin receptor mRNA in human CD34+ cells by $\mathrm{CpG}$ (cytosine linked to guanine by a phosphate bound) ODN-2006, a toll-like receptor-9 (TLR9) ligand that shares a consensus sequence with the parvovirus (PV) B19 genome [27]. This report was highly evaluated and has been introduced in Hematology 2010, the American Society of Hematology Education Program Book (30th edition, p. 283) as an experimental result that provided insight into the mechanisms of PV B19 inhibition of erythropoiesis.

The search for Wonders in Erythropoiesis goes on, and our work in introducing them will continue necessarily to reflect a number of factors, such as the state of the science, clinical demand, and the sheer appeal of scientific curiosity. Scientific advances may also reveal new wonders to the field of erythropoiesis, and so although the content of the Seven Wonders of Erythropoiesis series may change over time, I believe these will continue to stand at the forefront of medical science.

\section{References}

1. Chasis JA, Mohandas N. Erythroblastic islands: niches for erythropoiesis. Blood. 2008;112:470-8.

2. Ji P, Jayapal SR, Lodish HF. Enucleation of cultured mouse fetal erythroblasts requires Rac GTPases and mDia2. Nat Cell Biol. 2008;10:314-21.
3. Chen K, Liu J, Heck S, Chasis JA, An X, Mohandas N. Resolving the distinct stages in erythroid differentiation based on dynamic changes in membrane protein expression during erythropoiesis. Proc Natl Acad Sci USA. 2009;106:17413-8.

4. Draptchinskaia N, Gustavsson P, Andersson B, et al. The gene encoding ribosomal protein S19 is mutated in Diamond-Blackfan anaemia. Nat Genet. 1999;21:169-75.

5. Liu JM, Ellis SR. Ribosomes and marrow failure: coincidental association or molecular paradigm? Blood. 2006;107:4583-8.

6. Ebert BL, Pretz J, Bosco J, et al. Identification of RPS14 as a 5qsyndrome gene by RNA interference screen. Nature. $2008 ; 451: 335-9$.

7. Giarratana MC, Kobari L, Lapillonne H, et al. Ex vivo generation of fully mature human red blood cells from hematopoietic stem cells. Nat Biotechnol. 2005;23:69-74.

8. Miharada K, Hiroyama T, Sudo K, Nagasawa T, Nakamura Y. Efficient enucleation of erythroblasts differentiated in vitro from hematopoietic stem and progenitor cells. Nat Biotechnol. 2006;24:1255-6.

9. Hiroyama T, Miharada K, Sudo K, Danjo I, Aoki N, Nakamura Y. Establishment of mouse embryonic stem cell-derived erythroid progenitor cell lines able to produce functional red blood cells. PLoS One. 2008;3:e1544.

10. Raaijmakers MH, Mukherjee S, Guo S, et al. Bone progenitor dysfunction induces myelodysplasia and secondary leukaemia. Nature. 2010;464:852-7.

11. Naveiras O, Nardi V, Wenzel PL, Hauschka PV, Fahey F, Daley GQ. Bone-marrow adipocytes as negative regulators of the haematopoietic microenvironment. Nature. 2009;460:259-63.

12. Butler JM, Nolan DJ, Vertes EL, et al. Endothelial cells are essential for the self-renewal and repopulation of Notch-dependent hematopoietic stem cells. Cell Stem Cell. 2010;6:251-64.

13. Cantor AB, Orkin SH. Transcriptional regulation of erythropoiesis: an affair involving multiple partners. Oncogene. 2002;21: 3368-76.

14. Kaneko H, Shimizu R, Yamamoto M. GATA factor switching during erythroid differentiation. Curr Opin Hematol. 2010;17: $163-8$.

15. De Domenico I, McVey Ward D, Kaplan J. Regulation of iron acquisition and storage: consequences for iron-linked disorders. Nat Rev Mol Cell Biol. 2008;9:72-81.

16. Camaschella C, Roetto A, Cali A, et al. The gene TFR2 is mutated in a new type of haemochromatosis mapping to $7 \mathrm{q} 22$. Nat Genet. 2000;25:14-5.

17. Park CH, Valore EV, Waring AJ, Ganz T. Hepcidin, a urinary antimicrobial peptide synthesized in the liver. J Biol Chem. 2001;276:7806-10.

18. Pigeon C, Ilyin G, Courselaud B, et al. A new mouse liverspecific gene, encoding a protein homologous to human antimicrobial peptide hepcidin, is overexpressed during iron overload. J Biol Chem. 2001;276:7811-9.

19. Nemeth E, Tuttle MS, Powelson J, et al. Hepcidin regulates cellular iron efflux by binding to ferroportin and inducing its internalization. Science. 2004;306:2090-3.

20. Roetto A, Camaschella C. New insights into iron homeostasis through the study of non-HFE hereditary haemochromatosis. Best Pract Res Clin Haematol. 2005;18:235-50.

21. Sawada K, Fujishima N, Hirokawa M. Acquired pure red cell aplasia: updated review of treatment. Br J Haematol. 2008;142: 505-14.

22. Sawada K, Hirokawa M, Fujishima N. Diagnosis and management of acquired pure red cell aplasia. Hematol Oncol Clin North Am. 2009;23:249-59.

23. Sawada K, Hirokawa M, Fujishima N, et al. Long-term outcome of patients with acquired primary idiopathic pure red cell aplasia receiving cyclosporine A. A nationwide cohort study in Japan for 
the PRCA Collaborative Study Group. Haematologica. 2007;92: 1021-8.

24. Hirokawa M, Sawada K, Fujishima N, et al. Long-term response and outcome following immunosuppressive therapy in thymomaassociated pure red cell aplasia: a nationwide cohort study in Japan by the PRCA collaborative study group. Haematologica. 2008;93:27-33.

25. Fujishima N, Sawada K, Hirokawa M, et al. Long-term responses and outcomes following immunosuppressive therapy in large granular lymphocyte leukemia-associated pure red cell aplasia: a
Nationwide Cohort Study in Japan for the PRCA Collaborative Study Group. Haematologica. 2008;93:1555-9.

26. Hirokawa M, Sawada K, Fujishima N, et al. Acquired pure red cell aplasia associated with malignant lymphomas: a nationwide cohort study in Japan for the PRCA Collaborative Study Group. Am J Hematol. 2009;84:144-8.

27. Guo YM, Ishii K, Hirokawa M, et al. CpG-ODN 2006 and human parvovirus B19 genome consensus sequences selectively inhibit growth and development of erythroid progenitor cells. Blood. 2010;115:4569-79. 